\title{
High intratumoral expression of fibroblast activation protein (FAP) in colon cancer is associated with poorer patient prognosis
}

\author{
Maria L. Wikberg • Sofia Edin • Ida V. Lundberg • \\ Bethany Van Guelpen • Anna M. Dahlin • \\ Jörgen Rutegård • Roger Stenling • Åke Öberg • \\ Richard Palmqvist
}

Received: 13 December 2012 / Accepted: 16 December 2012/Published online: 18 January 2013

(C) The Author(s) 2013. This article is published with open access at Springerlink.com

\begin{abstract}
An active stroma is important for cancer cell invasion and metastasis. We investigated the expression of fibroblast activation protein (FAP) in relation to patient prognosis in colorectal cancer. Colorectal cancer specimens from 449 patients were immunohistochemically stained with a FAP antibody and evaluated in the tumor center and tumor front using a semiquantitative four-level scale. FAP was expressed by fibroblasts in $85-90 \%$ of the tumors examined. High versus no/low expression in the tumor center was associated with poor prognosis (multivariate hazard ratio, $\mathrm{HR}=1.72$; $95 \%$ CI $1.07-2.77, p=0.025$ ). FAP expression in the tumor front, though more frequent than in the tumor center, was not associated with prognosis. FAP expression in the tumor center was more common in specimens with positive microsatellite instability (MSI) screening status and in patients with high $\mathrm{CpG}$ island methylator phenotype (CIMP) status. However, inclusion of MSI screening status and CIMP status in the multivariate analysis strengthened the risk estimates for high FAP expression in the tumor center $(\mathrm{HR}=1.89$; $95 \%$ CI $1.13-$ $3.14 ; p=0.014$ ), emphasizing the role of FAP as an independent prognostic factor. Stromal FAP expression is common in colorectal cancer, and we conclude that high FAP expression in the tumor center, but not the tumor front, is an independent negative prognostic factor.
\end{abstract}

M. L. Wikberg $(\bowtie) \cdot$ S. Edin • I. V. Lundberg • B. Van Guelpen • A. M. Dahlin $\cdot$ R. Stenling $\cdot$ R. Palmqvist

Department of Medical Biosciences, Pathology, Umeå University, Building 6M, 2nd floor,

Umea SE-901 85, Sweden

e-mail: maria.wikberg@medbio.umu.se

J. Rutegård $\cdot$ Å. Öberg

Department of Surgical and Perioperative Sciences, Surgery,

Umeå University, Umeå, Sweden
Keywords Colorectal cancer $\cdot$ Fibroblast $\cdot$ Prognosis · Microsatellite instability $\cdot$ CIMP

\section{Introduction}

Colorectal cancer (CRC) is one of the most frequent cancers with regard to incidence and lethality for both men and women in the western world. Although the adenoma-carcinoma sequence is believed to underlie the development of CRC in most patients, the disease demonstrates considerable molecular heterogeneity, the putative prognostic importance of which is increasingly being recognized. By clustering particular genetic alterations, two distinctive pathways have been identified: microsatellite stability (MSS) and microsatellite instability (MSI). MSS tumors show frequent chromosomal gains and losses [1], and carcinogenesis is considered to be promoted by copy number gains of oncogenes and losses of tumor suppressors. MSI tumors, on the other hand, have loss of expression of mismatch repair genes, commonly $\mathrm{MLH1}$ in sporadic CRC. MSI tumors are generally less aggressive then MSS cancers and are less often associated with lymph node metastases or distant spread. Patients with MSI tumors also have better prognosis than stage-matched MSS patients [2-5]. MSI is highly associated with the $\mathrm{CpG}$ island methylator phenotype (CIMP) [6], in which gene promoter regions are frequently hypermethylated with resultant gene silencing. Depending on the frequency of promoter hypermethylation, tumors are classified as CIMP high, CIMP low, or CIMP negative. We and others have reported a worse prognosis in CRC patients with CIMP-high or CIMP-low tumors, compared to patients 
with CIMP-negative tumors, especially in combination with MSS [7-14].

Fibroblast activation protein (FAP) (also called seprase) is a type II integral membrane protein belonging to the family of plasma membrane-bound serine proteases $[15,16]$. It shows gelatinase and collagenase activity, suggesting a role in extracellular matrix remodeling [17]. It was originally reported to be localized on human astrocytes and sarcoma cell lines in vitro [18, 19] and was later found to be expressed also in fibroblasts in many epithelial cancers, including CRC [15, 16, 19, 20]. Few previous studies have addressed the role of FAP in CRC prognosis, and none have taken into consideration the molecular heterogeneity within CRC. Henry et al. [21] showed that high FAP expression in patients with known metastases indicates a more rapid progression of the disease, and a study by Saigusa et al. [22] suggests that high FAP expression in rectal cancers after preoperative chemoradiotherapy is associated with a poorer prognosis.

In this study, we evaluated the frequency, degree, and distribution of FAP expression in CRC tissue and related the findings to clinical outcome, accounting for MSI screening status and CIMP status. It is, to our knowledge, the largest such study to date and the first to take into consideration the molecular heterogeneity of CRC.

\section{Material and methods}

\section{Clinical samples}

The 488 CRC cases initially included in the present study were from the Colorectal Cancer in the Umea Study (CRUMS), which consists of patients with primary CRC, who underwent tumor-resective surgery during the period 1995-2003 at Umeå University Hospital, Sweden. Of these, 33 and 30 patients (tumor center and tumor front, respectively) were excluded due to lack of adequate tissue available (i.e., tumor front not included in the specimen or inadequate FAP staining results). An additional 35 patients lacked follow-up data or died with operative complications, leaving 420 (tumor center) and 423 (tumor front) patients for the survival analyses.

All tumor sections were reviewed by one pathologist, who also did all histopathological classifications including stage, grade, and histological type (mucinous or non-mucinous). Clinical data were obtained by reviewing patient records, and survival data were collected during spring 2005. The study was approved by the local ethical committee of Umeå University, Umeå, Sweden.
Immunohistochemistry

Immunohistochemistry using a FAP antibody was performed as previously described [20]. Briefly, specimens were fixed in $4 \%$ formaldehyde and embedded in paraffin, according to routine procedures at the Department of Clinical Pathology, Umeå University Hospital, Sweden. One 4$\mu \mathrm{m}$ section from each patient was cut, dried, dewaxed, and rehydrated. Slides were then subjected to heat-mediated antigen retrieval using BORG solution (Histolab, Gothenburg, Sweden) in a Decloaker ${ }^{\mathrm{TM}}$ pressure cooker. Anti-FAP monoclonal antibody (D8, Vitatex, Stony Brook, NY, USA) was used at a concentration of 1:100, and Rat-on-MouseHRP Polymer Detection kit (Biocare Medical, Concord, CA, USA) was applied for detection. The slides were counterstained with hematoxylin.

For FAP evaluation, slides were reviewed under light microscopy by one observer three times, and the reviewer was blinded to the identity of the specimens between evaluations. Stromal staining was assessed as negative,,+++ , or +++ according to the semiquantitative scale suggested by Henry et al. [21]. Occasional epithelial staining was not analyzed. For the survival analyses, the negative, +, and ++ groups were combined in order to compare cancer-specific survival of tumors with no/low and high $(+++)$ FAP expression. FAP immunostaining was evaluated both in fibroblasts localized in stroma adjacent to the invasive tumor margin (tumor front) and fibroblasts localized in the stroma within the tumor mass (tumor center). Necrotic areas and ulcerated luminal parts were avoided. In cases of heterogeneity, the score that was most representative for the entire section was assigned.

\section{Microsatellite instability screening status}

Immunohistochemical analyses of mismatch repair proteins were performed as previously described [7, 23]. Briefly, formalin-fixed and paraffin-embedded CRC tissue was analyzed for expression of the four mismatch repair (MMR) proteins MLH1 (clone G168-15, dilution 1:50; BD Biosciences Pharmingen, Belgium), MSH2 (clone FE11, 1:50; Oncogene Research Products, San Diego, CA), MSH6 (clone 44, 1:50; BD Biosciences Pharmingen), and PMS2 (A16-4, 1:25; BD Biosciences, Belgium). Tissue samples with tumor cells lacking nuclear staining for at least one of these proteins were considered to have a positive MSI screening status, hereafter referred to as MSI. Negative MSI screening status based on immunohistochemical staining is hereafter referred to as MSS. MSI screening status examined with immunohistochemistry for MMR protein expression reflects MSI high status very well, with a sensitivity rate of $\sim 92 \%$ and specificity of $\sim 100 \%$ [24-26], but does not specify for MSI low [27]. Cases without internal 
positive control staining, such as lymphocytes, were considered uninformative.

\section{CpG island methylator phenotype status}

Methylation analysis to determine tumor CIMP status was performed by the MethyLight method (quantitative real-time PCR), with primer and probe sequences as previously described [7, 20, 28]. Briefly, DNA extracted from formalin-fixed, paraffin-embedded CRC tissue was bisulfite treated and purified using the EZ DNA methylation kit (Zymo Research, Orange, CA, USA). For all bisulfite-treated DNA samples, one reaction was run for each of the eight genes included in the CIMP panel (CDKN2A, MLH1, CACNA1G, NEUROG1, RUNX3, SOCS1, IGF2, and CRABP1) [7]. The percent of methylated reference (PMR) value was calculated for each gene [28]. Samples were considered positive for methylation when an exponential amplification curve was present and generated a PMR $>10$ [28]. Tumors with promoter hypermethylation in zero genes were classified as CIMP negative, one to five genes as CIMP low, and six to eight genes as CIMP high [7].

\section{Statistics}

Cross tabulations were analyzed with Pearson Chi-square test when at least one cell had an observed or expected frequency less than five. To test the linear association between two ordinal scale variables, the exact linear-by-linear association test was performed. The Kaplan-Meier survival plots were used to illustrate cancer-specific survival, and comparisons between groups were performed by log-rank test. Cancer-specific events were defined as death with known disseminated or recurrent disease, and cases were censored at the end of follow-up or at time of death by other causes, whichever occurred first. In order to take into consideration other clinicopathological factors, multivariate Cox proportional hazard models were employed. Statistical analyses were performed using SPSS/PASW statistical software version 18.0. The $p$ values $<0.05$ were considered statistically significant.

\section{Results}

Frequencies

Colorectal carcinoma tissue samples from 449 patients were successfully immunohistochemically evaluated for stromal FAP expression (455 and 458 cases for tumor center and tumor front, respectively). Representative staining is shown in Fig. 1. In the tumor center, $72(15.8 \%)$ were negative, $215(47.3 \%)$ were,+ 113 were $(24.8 \%)++$, and 55 $(12.1 \%)$ were +++ (Table 1). In contrast, in the tumor front, only $47(10.3 \%)$ were negative, 114 (24.9\%) were +, 137 $(29.9 \%)$ were ++, and 160 (34.9\%) were +++ (Table 2). However, FAP expression in the tumor center was correlated to expression in the tumor front $\left(r_{\mathrm{s}}=0.29 ; p<0.001\right)$.

\section{Clinicopathological data}

FAP expression in the tumor center and tumor front in relation to clinicopathological variables is presented in Tables 1 and 2, respectively. Tumors of mucinous type expressed lower levels of FAP in the tumor front compared with non-mucinous
Fig. 1 Representative examples of FAP immunohistochemical staining of stromal cells in colorectal cancers. a Low $(+)$ staining in the tumor center, $\mathbf{b}$ strong $(+++)$ staining in the tumor center, $\mathbf{c}$ low $(+)$ staining in the tumor front, $\mathbf{d}$ strong $(+++)$ staining in the tumor front
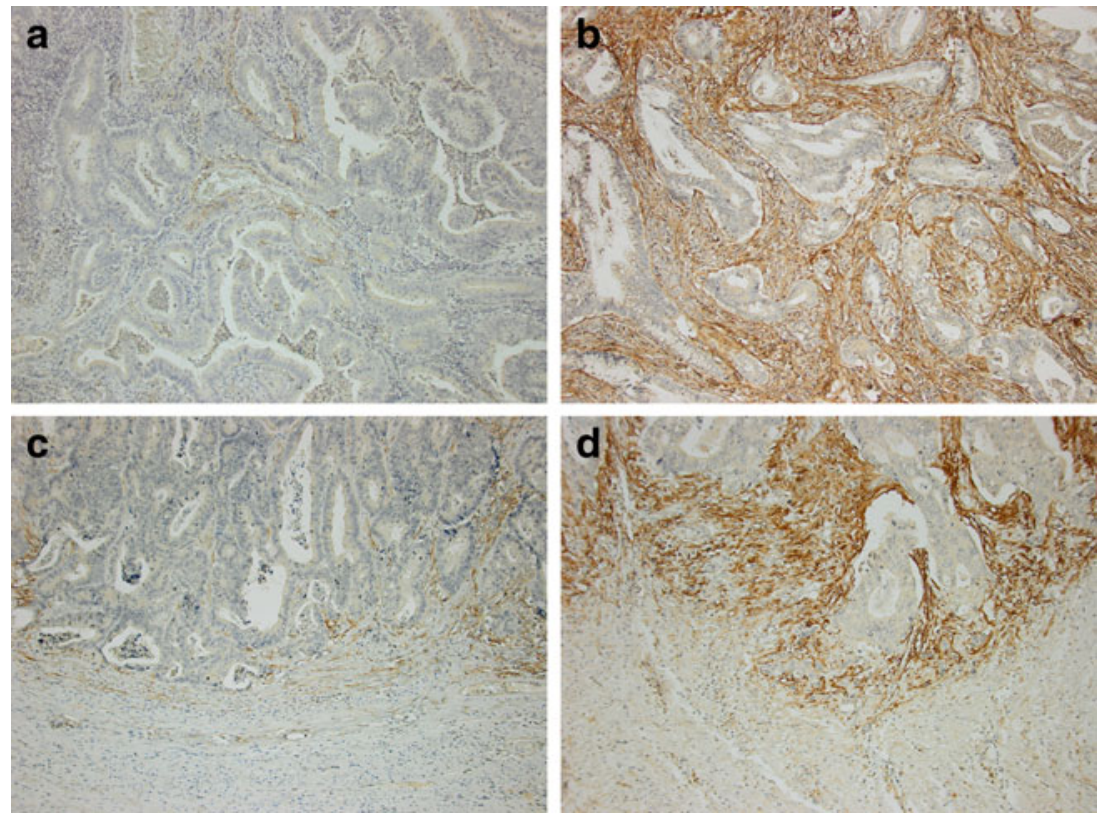
Table 1 Clinicopathological characteristics in relation to FAP expression in the tumor center in colorectal cancer

\begin{tabular}{|c|c|c|c|c|c|}
\hline & \multicolumn{3}{|c|}{ FAP expression tumor center } & \multirow[b]{2}{*}{+++} & \multirow[b]{2}{*}{$p$ value $^{\mathrm{a}}$} \\
\hline & Negative & + & ++ & & \\
\hline $\begin{array}{c}\text { Frequencies, } \\
n(\%)^{\mathrm{b}}\end{array}$ & $72(15.8)$ & $215(47.3)$ & $113(24.8)$ & $55(12.1)$ & \\
\hline \multicolumn{6}{|l|}{ Sex, $n(\%)$} \\
\hline Male & $41(16.4)$ & $107(42.8)$ & $65(26.0)$ & $37(14.8)$ & \\
\hline Female & $31(15.1)$ & $108(52.7)$ & $48(23.4)$ & $18(8.8)$ & 0.106 \\
\hline \multicolumn{6}{|l|}{ Age, $n(\%)$} \\
\hline$\leq 59$ years & $13(14.9)$ & $40(46.0)$ & $23(26.4)$ & $11(13.4)$ & \\
\hline $60-69$ years & $18(15.8)$ & $58(50.9)$ & $26(22.8)$ & $11(10.2)$ & \\
\hline $70-79$ years & $23(14.6)$ & $72(45.9)$ & $39(24.8)$ & $23(14.6)$ & \\
\hline 80 years & $18(18.6)$ & $45(46.4)$ & $25(25.8)$ & $9(9.3)$ & 0.960 \\
\hline \multicolumn{6}{|c|}{ Localization, $n(\%)$} \\
\hline Right colon & $19(13.0)$ & $72(49.3)$ & $28(19.2)$ & $27(18.5)$ & \\
\hline Left colon & $27(18.8)$ & $71(49.3)$ & $32(22.2)$ & $14(9.7)$ & \\
\hline Rectum & $23(14.3)$ & $72(44.7)$ & $52(32.3)$ & $14(8.7)$ & 0.019 \\
\hline \multicolumn{6}{|l|}{ TNM stage, $n(\%)$} \\
\hline I & $11(15.9)$ & $32(46.4)$ & $20(29.0)$ & $6(8.7)$ & \\
\hline II & $28(15.9)$ & $78(44.3)$ & $53(30.1)$ & $17(9.7)$ & \\
\hline III & $12(12.9)$ & $46(49.5)$ & $19(20.4)$ & $16(17.2)$ & \\
\hline IV & $18(16.8)$ & $55(51.4)$ & $19(17.8)$ & $15(14.0)$ & 0.310 \\
\hline \multicolumn{6}{|l|}{ Grade, $n(\%)$} \\
\hline High-moderate & $40(17.7)$ & $115(50.9)$ & $50(22.1)$ & $21(9.3)$ & \\
\hline Moderate-poor & $32(14.3)$ & $97(43.5)$ & $60(26.9)$ & $340(15.2)$ & 0.095 \\
\hline \multicolumn{6}{|c|}{ Tumor type, $n(\%)$} \\
\hline Mucinous & $15(21.1)$ & $36(50.7)$ & $10(14.1)$ & $10(14.1)$ & \\
\hline Non-mucinous & $55(14.6)$ & $178(47.1)$ & $100(26.5)$ & 45 (11.9) & 0.122 \\
\hline \multicolumn{6}{|c|}{ Preoperative radiotherapy ${ }^{\mathrm{c}}, n(\%)$} \\
\hline No & $55(15.9)$ & $177(51.0)$ & $72(20.7)$ & $43(12.4)$ & \\
\hline Yes & $16(15.2)$ & $37(35.2)$ & $40.8(38.1)$ & $12(11.4)$ & 0.003 \\
\hline
\end{tabular}

${ }^{\text {a }}$ Pearson Chi-square test

${ }^{\mathrm{b}}$ Row percentage

${ }^{\mathrm{c}}$ Rectal cancer

tumors. High FAP expression in the tumor center was most prevalent in right-sided CRC, whereas high FAP expression in the tumor front was most prevalent in rectal cancer. FAP expression in the tumor front was negatively associated with tumor stage, with higher levels of FAP in the tumor front of stage I patients. In contrast, FAP expression in the tumor center was not related to tumor stage.

Preoperative radiotherapy of rectal cancers is a potential confounding factor, and a significant positive association between radiotherapy and FAP expression in the tumor center was found.

FAP expression and MSI screening status and CIMP

Table 3 shows FAP expression in relation to MSI screening status and CIMP status. High expression of FAP in the
Table 2 Clinicopathological characteristics in relation to FAP expression in the tumor front in colorectal cancer

\begin{tabular}{|c|c|c|c|c|c|}
\hline & \multicolumn{3}{|c|}{ FAP expression tumor front } & \multirow[b]{2}{*}{+++} & \multirow[b]{2}{*}{$p$ value $^{\mathrm{a}}$} \\
\hline & Negative & + & ++ & & \\
\hline $\begin{array}{c}\text { Frequencies, } \\
n(\%)^{\mathrm{b}}\end{array}$ & $47(10.3)$ & $114(24.9)$ & $137(29.9)$ & $160(34.9)$ & \\
\hline \multicolumn{6}{|l|}{ Sex, $n(\%)$} \\
\hline Male & $23(9.2)$ & $63(25.2)$ & $71(28.4)$ & $93(37.2)$ & \\
\hline Female & $24(11.5)$ & $51(24.5)$ & $66(31.7)$ & $67(32.2)$ & 0.603 \\
\hline \multicolumn{6}{|l|}{ Age, $n(\%)$} \\
\hline$\leq 59$ years & $10(11.4)$ & $22(25.0)$ & $26(29.5)$ & $30(34.1)$ & \\
\hline $60-69$ years & $9(7.7)$ & $39(33.3)$ & $31(26.5)$ & $38(32.5)$ & \\
\hline $70-79$ years & $22(14.0)$ & $40(25.5)$ & $44(28.0)$ & $51(32.5)$ & \\
\hline 80 years & $6(6.3)$ & $13(13.5)$ & $36(37.5)$ & $41(42.7)$ & 0.041 \\
\hline \multicolumn{6}{|c|}{ Localization, $n(\%)$} \\
\hline Right colon & $22(14.9)$ & $42(28.4)$ & $42(28.4)$ & $42(28.4)$ & \\
\hline Left colon & $15(10.5)$ & $35(24.5)$ & $46(32.2)$ & 47 (32.9) & \\
\hline Rectum & $7(4.3)$ & $36(22.1)$ & $49(30.1)$ & $71(43.6)$ & 0.006 \\
\hline \multicolumn{6}{|l|}{ Stage, $n(\%)$} \\
\hline I & $6(8.5)$ & $11(15.5)$ & $14(19.7)$ & $40(56.3)$ & \\
\hline II & $14(8.0)$ & $42(23.9)$ & $65(36.9)$ & $55(31.3)$ & \\
\hline III & $16(17.2)$ & $25(26.9)$ & $21(22.6)$ & $31(33.3)$ & \\
\hline IV & $10(9.3)$ & $33(30.6)$ & $34(31.5)$ & $31(28.7)$ & 0.001 \\
\hline \multicolumn{6}{|l|}{ Grade, $n(\%)$} \\
\hline High-moderate & $27(12.1)$ & $50(22.3)$ & $64(28.6)$ & $83(37.1)$ & \\
\hline Moderate-poor & $20(8.8)$ & $63(27.6)$ & $71(31.1)$ & $74(32.5)$ & 0.336 \\
\hline \multicolumn{6}{|c|}{ Tumor type, $n(\%)$} \\
\hline Mucinous & $17(24.3)$ & $23(32.9)$ & $12(17.1)$ & $18(25.7)$ & \\
\hline Non-mucinous & $30(7.9)$ & $90(23.6)$ & $122(31.9)$ & $140(36.6)$ & $<0.001$ \\
\hline \multicolumn{6}{|c|}{ Preoperative radiotherapy ${ }^{\mathrm{c}}, n(\%)$} \\
\hline No & $41(11.8)$ & $87(25.1)$ & $103(29.7)$ & $116(33.4)$ & \\
\hline Yes & $5(4.6)$ & $26(24.1)$ & $34(31.5)$ & $43(39.8)$ & 0.152 \\
\hline
\end{tabular}

${ }^{\text {a }}$ Pearson Chi-square test

${ }^{\mathrm{b}}$ Row percentage

${ }^{\mathrm{c}}$ Rectal cancer

tumor center was associated with MSI and CIMP high. FAP expression in the tumor front was not related to either MSI screening status or CIMP status.

\section{Cancer-specific survival and FAP expression}

Cancer-specific survival was shortest for CRC patients with high versus no/low FAP expression in the tumor center (Fig. 2a). This finding was attributable to the subgroup of patients with colon, but not rectal, cancer (Fig. 2c and d). FAP expression in the tumor front was not related to prognosis (Fig. 2b). In a multivariate Cox proportional hazard model including age, sex, tumor localization, stage, tumor type, and FAP, the poor prognosis for patients with high versus no/low FAP 
Table 3 FAP expression in relation to MSI and CIMP in tumor center and front

\begin{tabular}{|c|c|c|c|c|c|c|c|c|c|c|}
\hline & \multicolumn{5}{|c|}{ FAP tumor center } & \multicolumn{5}{|c|}{ FAP tumor front } \\
\hline & Negative & + & ++ & +++ & $p$ value $^{\mathrm{a}}$ & Negative & + & ++ & +++ & $p$ value $^{\mathrm{a}}$ \\
\hline \multicolumn{11}{|c|}{ MSI screening status ${ }^{\mathrm{b}}, n(\%)^{\mathrm{c}}$} \\
\hline MSI & $7(10.1)$ & $25(36.2)$ & $17(24.6)$ & $20(29.0)$ & & $9(13.2)$ & $22(32.4)$ & $12(17.6)$ & $25(36.8)$ & \\
\hline MSS & $64(17.2)$ & $184(49.5)$ & $93(25.0)$ & $31(8.3)$ & $<0.001$ & $37(9.8)$ & $88(23.4)$ & $123(32.7)$ & $128(34.0)$ & 0.074 \\
\hline \multicolumn{11}{|c|}{ CIMP status $(n, \%)$} \\
\hline CIMP neg & $39(17.3)$ & $109(48.2)$ & $60(28.2)$ & $15(7.0)$ & & $22(9.6)$ & $53(23.2)$ & $66(28.9)$ & $87(38.2)$ & \\
\hline CIMP low & $29(17.1)$ & $82(48.2)$ & $37(21.8)$ & $22(12.9)$ & & $16(9.4)$ & $40(23.5)$ & $60(35.3)$ & $54(31.8)$ & \\
\hline CIMP high & $4(6.9)$ & $24(41.4)$ & $13(22.4)$ & $17(29.3)$ & $<0.001$ & $9(15.3)$ & $21(35.6)$ & $11(18.6)$ & $18(30.5)$ & 0.108 \\
\hline
\end{tabular}

CIMP negative zero genes hypermethylated, CIMP low one to five genes hypermethylated, CIMP high six to eight genes hypermethylated

${ }^{\text {a }}$ Pearson Chi-square test

${ }^{\mathrm{b}}$ Cases lacking nuclear staining of tumor cells for at least one of MLH1, MSH2, MSH6 or PMS2 were considered to have a positive MSI screening status (MSI)

${ }^{\mathrm{c}}$ Row percentage

expression in the tumor center retained statistical significance (hazard ratio $(\mathrm{HR})=1.72$, CI 1.07-2.76, $p=$ 0.026). In line with the Kaplan-Meier analysis, FAP expression in the tumor front was not associated with survival in multivariate analysis. Further analyses are therefore limited to FAP expression in the tumor center.

Cancer-specific survival and FAP expression according to MSI screening status and CIMP status

High versus no/low FAP expression in the tumor center was associated with a shorter survival in both MSS and MSI subgroups (log-rank $p=0.013$ and $p=0.046$, respectively). Further, adjusting the multivariate Cox proportional hazard model (see above) for MSI screening status strengthened the risk estimate for FAP expression in the tumor center $(\mathrm{HR}=2.00$; CI 1.22-3.31; $p=0.007)$.

Cancer-specific survival analysis of different CIMP groups demonstrated a poorer prognosis for patients with CIMPnegative and CIMP-low tumors with high versus no/low FAP expression in both CRC (Fig. 3a and b) and colon cancer (Fig. 3d and e), but not rectal cancer (data not shown). FAP expression in the tumor center was not related to CRC or colon cancer prognosis in the subgroup of CIMP-high tumors (Fig. 3c and f). Adding CIMP status to the Cox proportional hazard model for CRC (including MSI status, see above) did not materially affect the risk estimate for high FAP expression in the tumor center $(\mathrm{HR}=1.89$; CI 1.13-3.14; $p=0.014)$.

\section{Discussion}

In the present study, we investigated the relationship of FAP expression in different tumor compartments in CRC in relation to clinicopathological variables and prognosis, taking into consideration MSI screening status and CIMP status. Tumors that were MSI or CIMP high expressed more FAP in the tumor center compared to MSS, CIMP-negative, and CIMP-low tumors. High expression of FAP in the tumor center also predicted a poor patient prognosis in all CRC patient groups studied, with the exception of CIMP high and rectal cancer. FAP expression in the tumor front was not associated with patient prognosis.

FAP has been described to be present in the tumor stroma of epithelial cancers $[15,16,19,20]$, and analysis of its expression in cancer in relation to prognosis has so far only been conducted in a few studies [21, 22, 29]; the few previous investigations of its expression in CRC have supported a negative prognostic role. The present study is, to the best of our knowledge, by far the largest study of clinical characterization of FAP in CRC and the only one to assess FAP expression in relation to heterogeneity within the tumor. We and others have previously seen that FAP expression is essentially a prerequisite for invasion in CRC $[20,21]$, and in the present study, only $10 \%$ of the patients lacked FAP in the tumor front. The degree of FAP positivity in the tumor front is variable, but, interestingly, this seems not to impact on prognosis. We speculate that FAP expression by fibroblasts in the tumor front may reflect a stress response to the microenvironment at the invasive margin, whereas FAP expression in the more sheltered tumor center might be a better indicator of the inherent invasive potential of the tumor. Henry et al. [21] suggested that FAP-expressing fibroblasts in the tumor front are of importance during early invasion, which might explain our finding of high FAP expression in the tumor front of stage I patients. Once the invasive carcinoma is established, other factors 

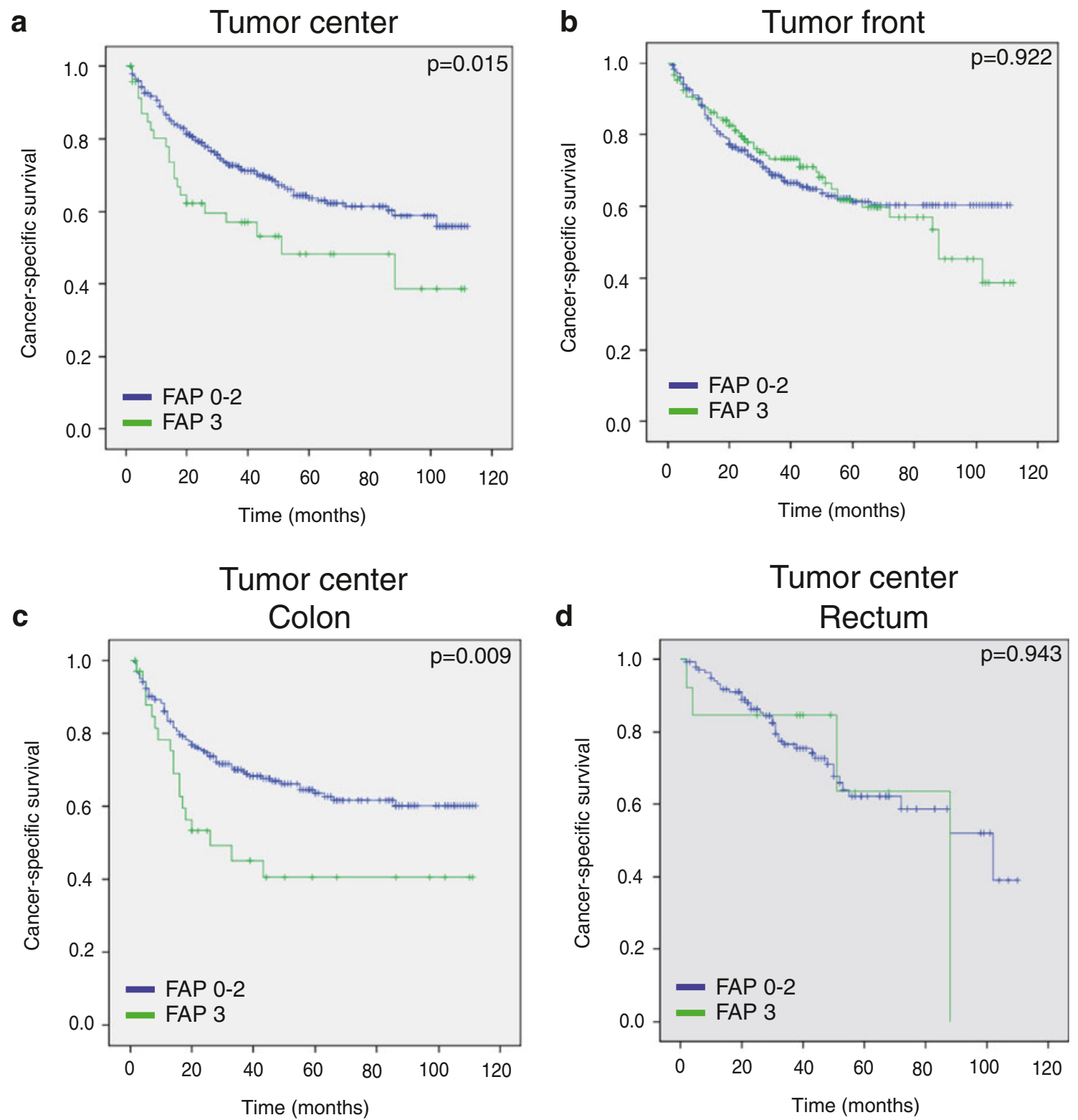

Fig. 2 Cancer-specific survival according to FAP expression in fibroblasts in: a CRC patients evaluated at the tumor center, b CRC patients evaluated at the tumor front, $\mathbf{c}$ colon cancer patients evaluated at the tumor center, $\mathbf{d}$ rectal cancer patients evaluated at the tumor center

appear to be more important for clinical outcome. We have recently shown that FAP-expressing fibroblasts produce fibroblast growth factor 1 , which increases the invasion of colon cancer cells [20] and might be one explanation for the poor prognosis seen in patients with high intratumoral FAP expression. Further studies are needed to fully understand the role of FAP-expressing fibroblasts in the tumor front of CRC.

In the present study, FAP expression in the center of the tumor was strongly associated with poorer patient prognosis, largely independent of other clinicopathological characteristics including MSI screening status and CIMP status. Only in the CIMP-high and rectal cancer patient groups did FAP expression in the tumor center not predict survival. The discrepancy in results between the largely overlapping patient groups of MSI and CIMP high could not be fully explored due to limited statistical power, and further investigation is warranted. CRC patients with MSI tumors had more stromal FAP in the tumor center, compared to the other patient groups. This was unexpected, since MSI is considered to be a positive prognostic marker [30,31] and was so in our study group as well [7].

We also found that low FAP expression in the tumor center was more common in rectal tumors without versus with preoperative radiotherapy. This might simply be due to the fact that radiotherapy itself induces cell damage, and FAP expression in these cases could reflect tissue remodeling 

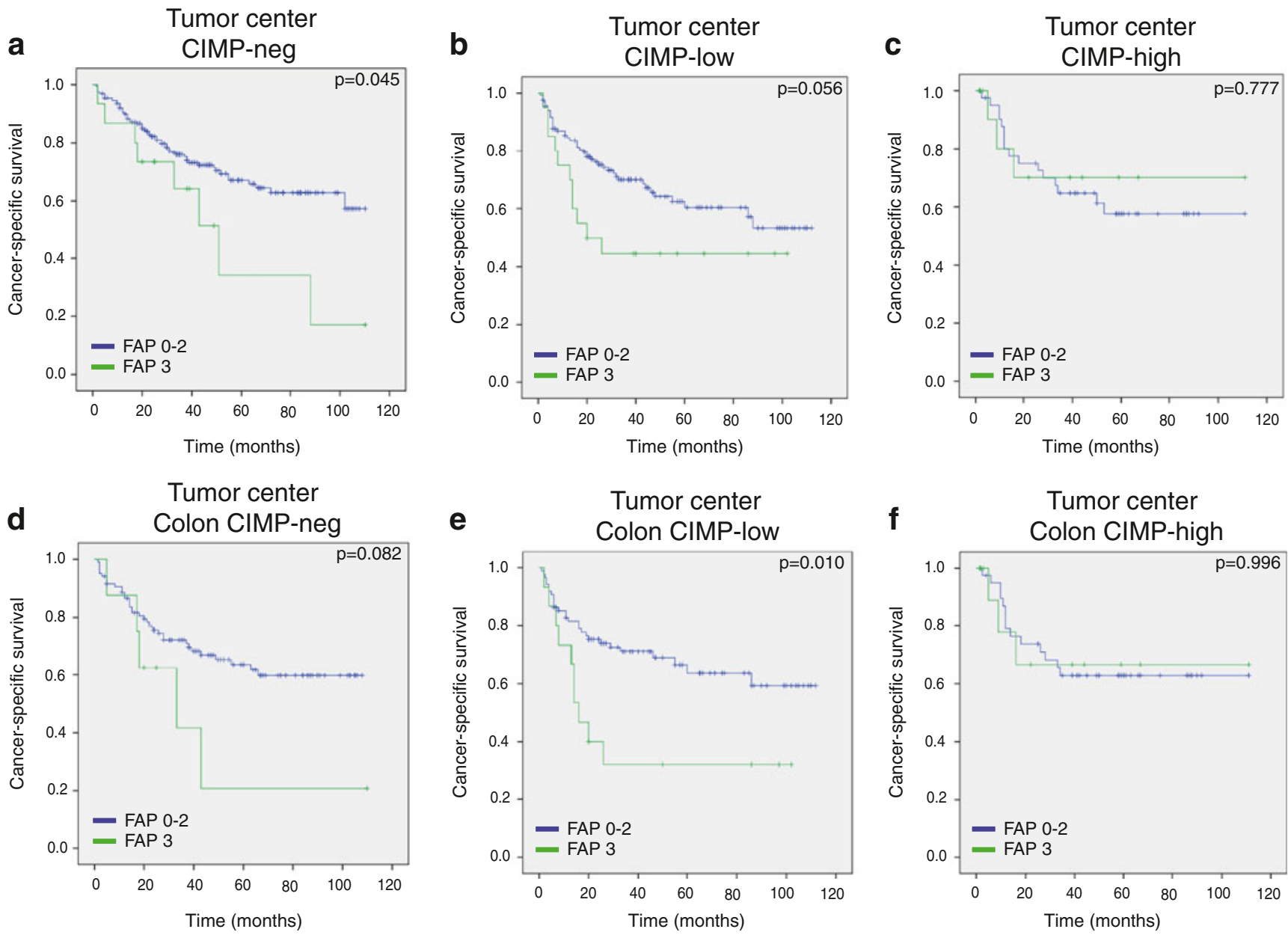

Fig. 3 Cancer-specific survival analysis according to FAP expression in fibroblasts in the tumor center. a CIMP-negative CRC patients. b CIMP-low CRC patients. c CIMP-high CRC patients. d CIMP-

in wound healing. This might also explain the high FAP expression in the tumor front of rectal carcinomas, since many of these patients had preoperative radiotherapy. Saigusa et al. [22] recently suggested that FAP expression in fibroblasts is related to poor prognosis in chemoradiotherapy-treated rectal cancer patients, but we could not confirm this observation in our patient cohort.

The main strength of this study was the large, wellcharacterized patient group. Extensive clinicopathological data allowed us to take into consideration a number of potential confounders, including sex, age at diagnosis, tumor location, tumor stage, mucinous histological type, MSI screening status, and CIMP status. MSI screening status was determined by IHC. Although MSI testing of standard markers by PCR allows distinction between MSI high and MSI low [27] and is the gold standard for determination of MSI status, several studies have reported very high sensitivity and specificity for IHC for the detection of MSI high [24-26]. Despite the large sample size, numbers of patients in some subgroup analyses were low. negative colon cancer patients. e CIMP-low colon cancer patients. f CIMP-high colon cancer patients

In conclusion, the results of this investigation of a large, well-characterized CRC patient group suggest that high FAP expression in the tumor center, but not the tumor front, is predictive of poorer patient prognosis, largely independent of clinicopathological factors, including MSI screening status and CIMP status.

Acknowledgments The authors thank Mrs Kerstin Näslund, Department of Medical Biosciences, Pathology, Umeå University, for skillful technical assistance. This study was supported by grants from Petrus and Augusta Hedlunds Foundation, the Swedish Cancer Foundation, Cutting-Edge Research Grant from the County Council of Västerbotten, Sweden, Magn Bergvall Foundation, the Swedish Research Council, and Lion's Cancer Research Foundation in Umeå, Sweden.

\section{Conflicts of interest None}

Open Access This article is distributed under the terms of the Creative Commons Attribution License which permits any use, distribution, and reproduction in any medium, provided the original author(s) and the source are credited. 


\section{References}

1. Grady WM. Genomic instability and colon cancer. Cancer Metastasis Rev. 2004;23:11-27.

2. Gryfe R, Kim H, Hsieh ET, Aronson MD, Holowaty EJ, Bull SB, Redston M, Gallinger S. Tumor microsatellite instability and clinical outcome in young patients with colorectal cancer. N Engl J Med. 2000;342:69-77.

3. Kohonen-Corish MR, Daniel JJ, Chan C, Lin BP, Kwun SY, Dent OF, Dhillon VS, Trent RJ, Chapuis PH, Bokey EL. Low microsatellite instability is associated with poor prognosis in stage c colon cancer. J Clin Oncol. 2005;23:2318-24.

4. Popat S, Hubner R, Houlston RS. Systematic review of microsatellite instability and colorectal cancer prognosis. J Clin Oncol. 2005;23:609-18.

5. Wright CM, Dent OF, Newland RC, Barker M, Chapuis PH, Bokey EL, Young JP, Leggett BA, Jass JR, Macdonald GA. Low level microsatellite instability may be associated with reduced cancer specific survival in sporadic stage c colorectal carcinoma. Gut. 2005;54:103-8.

6. Ahuja N, Mohan AL, Li Q, Stolker JM, Herman JG, Hamilton SR, Baylin SB, Issa JP. Association between cpg island methylation and microsatellite instability in colorectal cancer. Cancer Res. 1997;57:3370-4.

7. Dahlin AM, Palmqvist R, Henriksson ML, Jacobsson M, Eklof V, Rutegard J, Oberg A, Van Guelpen BR. The role of the cpg island methylator phenotype in colorectal cancer prognosis depends on microsatellite instability screening status. Clin Cancer Res. 2010;16:1845-55.

8. Morey AL, Wanigesekera GD, Hawkins NJ, Ward RL. C-kit mutations in gastrointestinal stromal tumours. Pathology. 2002;34:315-9.

9. Ward RL, Cheong K, Ku SL, Meagher A, O’Connor T, Hawkins NJ. Adverse prognostic effect of methylation in colorectal cancer is reversed by microsatellite instability. J Clin Oncol. 2003;21:3729-36.

10. Samowitz WS, Albertsen H, Herrick J, Levin TR, Sweeney C, Murtaugh MA, Wolff RK, Slattery ML. Evaluation of a large, population-based sample supports a cpg island methylator phenotype in colon cancer. Gastroenterology. 2005;129:837-45.

11. Barault L, Charon-Barra C, Jooste V, de la Vega MF, Martin L, Roignot P, Rat P, Bouvier AM, Laurent-Puig P, Faivre J, Chapusot C, Piard F. Hypermethylator phenotype in sporadic colon cancer: study on a population-based series of 582 cases. Cancer Res. 2008;68:8541-6.

12. Van Rijnsoever M, Elsaleh H, Joseph D, McCaul K, Iacopetta B. Cpg island methylator phenotype is an independent predictor of survival benefit from 5-fluorouracil in stage III colorectal cancer. Clin Cancer Res. 2003;9:2898-903.

13. Ogino S, Meyerhardt JA, Kawasaki T, Clark JW, Ryan DP, Kulke MH, Enzinger PC, Wolpin BM, Loda M, Fuchs CS. Cpg island methylation, response to combination chemotherapy, and patient survival in advanced microsatellite stable colorectal carcinoma. Virchows Arch. 2007;450:529-37.

14. Shen L, Catalano PJ, Benson 3rd AB, O’Dwyer P, Hamilton SR, Issa JP. Association between DNA methylation and shortened survival in patients with advanced colorectal cancer treated with 5-fluorouracil based chemotherapy. Clin Cancer Res. 2007; 13:6093-8.

15. Garin-Chesa P, Old LJ, Rettig WJ. Cell surface glycoprotein of reactive stromal fibroblasts as a potential antibody target in human epithelial cancers. Proc Natl Acad Sci U S A. 1990;87:7235-9.

16. Rettig WJ, Su SL, Fortunato SR, Scanlan MJ, Raj BK, GarinChesa P, Healey JH, Old LJ. Fibroblast activation protein: purification, epitope mapping and induction by growth factors. Int $\mathbf{J}$ Cancer. 1994;58:385-92.

17. Aggarwal S, Brennen WN, Kole TP, Schneider E, Topaloglu O, Yates M, Cotter RJ, Denmeade SR. Fibroblast activation protein peptide substrates identified from human collagen I derived gelatin cleavage sites. Biochemistry. 2008;47:1076-86.

18. Rettig WJ, Chesa PG, Beresford HR, Feickert HJ, Jennings MT, Cohen J, Oettgen HF, Old LJ. Differential expression of cell surface antigens and glial fibrillary acidic protein in human astrocytoma subsets. Cancer Res. 1986;46:6406-12.

19. Rettig WJ, Garin-Chesa P, Beresford HR, Oettgen HF, Melamed MR, Old LJ. Cell-surface glycoproteins of human sarcomas: differential expression in normal and malignant tissues and cultured cells. Proc Natl Acad Sci U S A. 1988;85:3110-4.

20. Henriksson ML, Edin S, Dahlin AM, Oldenborg PA, Oberg A, Van Guelpen B, Rutegard J, Stenling R, Palmqvist R. Colorectal cancer cells activate adjacent fibroblasts resulting in fgfl/fgfr 3 signaling and increased invasion. Am J Pathol. 2011;178:1387-94.

21. Henry LR, Lee HO, Lee JS, Klein-Szanto A, Watts P, Ross EA, Chen WT, Cheng JD. Clinical implications of fibroblast activation protein in patients with colon cancer. Clin Cancer Res. 2007;13:1736-41.

22. Saigusa S, Toiyama Y, Tanaka K, Yokoe T, Okugawa Y, Fujikawa H, Matsusita K, Kawamura M, Inoue Y, Miki C, Kusunoki M. Cancer-associated fibroblasts correlate with poor prognosis in rectal cancer after chemoradiotherapy. Int J Oncol. 2011;38:655-63.

23. Ljuslinder I, Melin B, Henriksson ML, Oberg A, Palmqvist R. Increased epidermal growth factor receptor expression at the invasive margin is a negative prognostic factor in colorectal cancer. Int J Cancer. 2011;128:2031-7.

24. Ruszkiewicz A, Bennett G, Moore J, Manavis J, Rudzki B, Shen L, Suthers G. Correlation of mismatch repair genes immunohistochemistry and microsatellite instability status in hnpcc-associated tumours. Pathology. 2002;34:541-7.

25. Lindor NM, Burgart LJ, Leontovich O, Goldberg RM, Cunningham JM, Sargent DJ, Walsh-Vockley C, Petersen GM, Walsh MD, Leggett BA, Young JP, Barker MA, Jass JR, Hopper J, Gallinger S, Bapat B, Redston M, Thibodeau SN. Immunohistochemistry versus microsatellite instability testing in phenotyping colorectal tumors. J Clin Oncol. 2002;20:1043-8.

26. Bertagnolli MM, Niedzwiecki D, Compton CC, Hahn HP, Hall M, Damas B, Jewell SD, Mayer RJ, Goldberg RM, Saltz LB, Warren RS, Redston M. Microsatellite instability predicts improved response to adjuvant therapy with irinotecan, fluorouracil, and leucovorin in stage III colon cancer: cancer and leukemia group b protocol 89803. J Clin Oncol. 2009;27:1814-21.

27. Boland CR, Thibodeau SN, Hamilton SR, Sidransky D, Eshleman JR, Burt RW, Meltzer SJ, Rodriguez-Bigas MA, Fodde R, Ranzani GN, Srivastava S. A national cancer institute workshop on microsatellite instability for cancer detection and familial predisposition: development of international criteria for the determination of microsatellite instability in colorectal cancer. Cancer Res. 1998;58:5248-57.

28. Weisenberger DJ, Siegmund KD, Campan M, Young J, Long TI, Faasse MA, Kang GH, Widschwendter M, Weener D, Buchanan D, Koh H, Simms L, Barker M, Leggett B, Levine J, Kim M, French AJ, Thibodeau SN, Jass J, Haile R, Laird PW. CpG island methylator phenotype underlies sporadic microsatellite instability and is tightly associated with BRAF mutation in colorectal cancer. Nat Genet. 2006;38:787-93.

29. Cohen SJ, Alpaugh RK, Palazzo I, Meropol NJ, Rogatko A, Xu Z, Hoffman JP, Weiner LM, Cheng JD. Fibroblast activation protein and its relationship to clinical outcome in pancreatic adenocarcinoma. Pancreas. 2008;37:154-8.

30. Lin CC, Lai YL, Lin TC, Chen WS, Jiang JK, Yang SH, Wang HS, Lan YT, Liang WY, Hsu HM, Lin JK, Chang SC. Clinicopathologic features and prognostic analysis of MSI-high colon cancer. Int J Colorectal Dis. 2012;27:277-86.

31. Boland CR, Goel A. Microsatellite instability in colorectal cancer. Gastroenterology. 2010;138:2073-87. e2073. 